\title{
Regulating Small and Medium Charities: Does it improve Transparency and Accountability?
}

\author{
Carolyn Cordery
}

Presented at the Panel titled: Charity Accounting, Regulation and Reporting at the 10th International Conference of ISTR (International Society for Third Sector Research), Siena 10-13 July 2012.

Published in Voluntas (2013) 24:831-851: DOI 10.1007/s11266-013-9381-6

This is a pre-production version - please follow the link to the published version

Author details: Carolyn Cordery, School of Accounting and Commercial Law, Victoria University of Wellington, PO Box 600 Wellington New Zealand. T: =64 4 4635761; E Carolyn.Cordery@vuw.ac.nz 


\title{
Regulating Small and Medium Charities: Does it improve Transparency and Accountability?
}

\begin{abstract}
:
Internationally, there has been a steady increase in the number of countries instigating charity regulation. Public interest theory suggests that regulation increases organizational transparency through reducing information asymmetry, protects (or encourages) a competitive market, and leads to a distribution of resources which is in the public interest. While these arguments may explain charity regulation, the cost of compliance can be an issue for small and medium-sized charities. Therefore regulators tend to take a light-handed approach to small and medium charities' information provision. This paper ascertains the impact of a light-handed enforcement regime on small and medium charities' reporting, analysing the financial reporting practices of a selection of 300 small and medium-sized charities registered with the former New Zealand Charities Commission against the Charities Act 2005 requirements and hence the rationale for this regulator. It uses this analysis to predict how the regulator's activities might impact future reporting practices of charities.
\end{abstract}

Key Words: Charity regulation, charity reporting, charity compliance, financial reporting. 


\section{Regulating small and medium charities: does it improve transparency and accountability?}

\section{Introduction}

Internationally, there has been a steady increase in the number of countries instigating charity regulation. As examples of independent regulators, the Charity Commission for England and Wales (CCEW) arose from arrangements that date back to the Charitable Trusts Acts of $1853^{1}$ with more recent entrants being the Office of the Scottish Charity Regulator (OSCR) (2003), the New Zealand's Charities Commission (2005), the Singaporean Charity Council (2007), the Charity Commission for Northern Ireland (2008) and the Australian Charities and Not-for-Profits Commission (ACNC) (2012). In other countries (such as Canada and the United States (US)) tax authorities register and monitor charitable activity. Charity watchdogs have also established in recent years. These include GuideStar in the US, United Kingdom (UK), India and now globally, and the Better Business Bureau's Wise Giving Alliance which reports on national and some regional charities in the US. As Szper and Prakash (2011, p.116) note "there is a perception, correct or incorrect, that nonprofits have transparency issues" and therefore that regulation is required to improve charities' transparency and accountability. The exemption from income tax enjoyed by charities and the donee concessions afforded by many registered charities are also reasons for regulation.

Public interest theory suggests that regulation increases transparency through reducing information asymmetry, protects (or encourages) a competitive market and leads to a distribution of resources which is in the public interest (Gaffikin, 2005). While these arguments are commonly used to call for regulation in the private (for-profit) sphere, nonetheless they may explain some of the increase in the number of charity regulators.

1 The 1853 Act appointed Commissioners, with the name change to CCEW being enacted by the Charities Act 2006, Section 6. 
For example due to the lack of 'owners', information asymmetry gives rise to the potential for opportunism in charities and other nonprofit organizations (Desai \& Yetman, 2005). In addition, Weisbrod (1989) notes that these organizations' managers have less incentive to be efficient than managers of for-profit businesses, and therefore require greater monitoring of their financial and social performance. These precepts derived from agency theory point to the need for both internal and external monitoring. In respect of external monitoring, Desai and Yetman (2005) found that US regulatory requirements for charities to return financial information leads to lower compensation of officers and directors and thus, maximises funds available for charitable distribution. ${ }^{2}$ Regulating for increased charity information may therefore build the donating public's trust and confidence (Hyndman \& McDonnell, 2009).

Notwithstanding a need for regulation, parsimony is an important aspect of good regulation (Simon, 1995), that is, regulation should not be heavier than necessary to achieve its aim. While regulators therefore require large charities to comply with minimum reporting standards, they tend to take a light-handed approach to small and medium charities' information provision for the sake of parsimony (for example, Hind, 2011; Morgan, 2010).

Recent articles in this Journal have focused on regulation of charitable funding (Barber, 2012; Breen, 2012; Phillips, 2012) - a subset of the issue of charity regulation, however this special issue considers the regulation of charities' financial reporting. Responding to the call by Hyndman and McDonnell (2009) for research into charities regulation, its rationale and operation, the objective of this paper is to ascertain the impact of a light-handed enforcement regime on small and medium charities' reporting. In so doing, it analyses the financial reporting practices of a selection of charities registered with the former New Zealand Charities Commission against the Charities Act requirements, and hence

2 This is despite the limited public access of US returns. Interested parties must request copies of filings from the charities rather than being able to download them from a central register. Nevertheless, for larger entities, Better Business Bureau's Wise Giving and GuideStar facilitate information access and commentary. 
the rationale for this regulator. ${ }^{3}$ It uses this analysis to predict how the regulator's activities might impact future filing practices of charities.

The paper proceeds as follows: first the rationale for charities' regulation and reporting is provided and tested against the oldest charity regulator (the CCEW). In section three the New Zealand context is described and the research design presented. Following the research results, the paper continues with a discussion and conclusion, including limitations and opportunities for further research.

\section{Regulation in the charities sector}

\subsection{The impetus to regulate}

A number of theories of regulation and the contextually and temporally specific nature of the need for and the imposition of regulation make discussions of regulation complex (Gaffikin, 2005). Stigler (1971) argues that government regulation can be a means to protect the public from the failures of self- or no- regulation. His public interest theory addresses concerns that private interest will outweigh the public interest in business operations and that, due to information asymmetry, regulation is needed to protect the public interest. Public interest theory suggests a regulator will facilitate activities in the private sphere to: (i) address information asymmetries in a manner equitable both to the regulated (preparer of the information) and to the users of the information, and (ii) to maintain an environment which encourages competition and fair distribution of resources (Gaffikin, 2005). Within such a regime, regulators are expected to set minimum standards, increase the amount of publicly available information and enhance comparability across entities (Brown, 1990). This will occur when the publicly available information is of sufficient quality and credibility.

Public interest arguments may also be adapted to explain regulation in the private charity sphere. In this sector, high information asymmetry exists due to the prevalence of unreciprocated (non-exchange)

3 Since 1 July 2012, the once independent Charities Commission has been replaced and the regulator is now within the Department of Internal Affairs. A three member Board has taken over the prior Commissioners' functions in respect of making decisions about registering and deregistering charities. 
contributions to charities (Weisbrod, 1989) and due to the lack of ownership (Desai \& Yetman, 2005). There is a great diversity of users and, for example, the UK Charities Act 2011 requires the CCEW to (amongst others) 'inspire public trust and confidence in charities' and to 'enhance the accountability of charities to donors, beneficiaries and the general public'. The CCEW enhances accountability by careful attention to information asymmetries of these users (donors, beneficiaries and the general public) and reports that public trust and confidence in charities continues to increase (Hind, 2011). Notwithstanding regulators' intentions to enhance accountability, incidences of fraud continue to occur as shown by Fremont and Kosaras (2003). Further, poor reporting by charities leads to a lack of transparency (as shown in section 2.3).

Regulation may also be developed to maintain competition in certain markets (Gaffikin, 2005). Competition is encouraged due to the belief that scarce resources will be distributed effectively and efficiently amongst those who pay for a market-provided service or good and the providing organizations. Further, regulation within a competitive market can lead to more just distribution of resources (Gaffikin, 2005). Potentially this rhetoric of the efficient market may be observed in charity regulation. For example, the UK Charities Act 2011 requires the CCEW to (amongst others) 'promote the effective use of charitable resources'. The manner in which the CCEW makes information available about large charities on its website, and the UK government's sponsorship of an information website (GuideStar) (see Dhanani, 2009) provide evidence of the regulator's desire to encourage competition in the charities market which may also lead to the more fair distribution of resources throughout the sector. This is all the more important, suggest Hyndman and McMahon (2011), due to the increasing amounts of government funding into the charities sector (especially for social services delivery). Hind (2011) also notes that a role of the CCEW has been to promote public interest in charity, and this also speaks of the creation of a public market.

Yet, the term 'public interest' may be ill-defined and these theories do not sufficiently consider the competence and independence of the regulator (Gaffikin, 2005). This is not such an issue in the charity 
case, as the public interest has been defined by statute ('promoting public trust and confidence in charities'), although it is recognised that robustly measuring trust and confidence can be difficult.

Public interest theory explains why industries might have regulation thrust upon it, however Stigler (1971) also discusses private interest theory, where industries actively seek regulation. This second rationale is useful in considering some regulatory frameworks (for example, Phillips, 2012 discusses the Canadian case), however it does not appear to explain the rise of New Zealand charity regulation (the context of this research). Indeed, self-regulation in the charities sector has occurred infrequently and has experienced only limited success (Cordery \& Baskerville, 2007; Phillips, 2012). Cordery and Baskerville (2007) note that when the New Zealand Government consulted on the need or otherwise for a Charities Commission (in its 'Tax and Charities' review of 2001) a majority of the 1682 submissions supported or accepted the need for an external regulator of the charitable sector, rather than arguing for self-regulation.

An issue with self-regulation is regulatory capture, due to a lack of independence (perceived or otherwise) (Gaffikin, 2005). The vision of the CCEW notes it is to be 'the independent regulator for charitable activity...' Its independence ensures that interest groups (including government, charities themselves and, to a lesser extent the public) cannot capture the regulator. Independence also means that the regulator will sanction a charity's short-comings by de-registration and, in extreme cases, convictions through the court process. Thus, the regulator's process needs to be open, transparent, accountable and acceptable.

Charities' regulators tend to use compliance approaches to encourage and educate charities rather than enforcing requirements through deterrence approaches. A compliance approach is flexible and less confrontational (Gaffikin, 2005), as can be observed with the CCEW which viewed its role in the early $21^{\text {st }}$ century, as "being akin to regulating angels" (Hind, 2011, p. 202). The benefits of a compliance approach are that regulation can be carried out more efficiently and therefore with less cost. Yet, compliance approaches are more susceptible to being captured by interest groups and may 
lead to a lack of sufficient regulatory resources (Gaffikin, 2005). Compliance monitoring is evident from the manner in which charities regulators assume an education role.

Regulation requires charities to disclose financial and also non-financial information about the difference they make within communities to meet users' needs for accountability and for information to make decisions about future donations and relationships with charities. Users of charities' reports are diverse and their needs are potentially varied. In the United Kingdom (UK), Bird and Morgan-Jones (1981) asserted that there are six user types. The New Zealand Institute of Chartered Accountants' (2007) Not-for-Profit Financial Reporting Guide lists 13 different users who could rely on charities' financial reports for information. Users may be internal (for example, staff, board members and volunteers) or external, providing resources to the organization, and/or seeking accountability for external support by way of various fiscal concessions. No doubt a number of these users were responsible for the 14 million 'hits' on the New Zealand Charities register during the 2010 calendar year. $^{4}$

\subsection{Arguments against regulation}

Notwithstanding, some users will seek information elsewhere than a public register and may argue that regulation is not required. For other donors the 'warm glow' of giving (Andreoni, 1998) will be sufficient, making them less likely to make enquiries as to charities' performance. Hyndman and McDonnell (2009) suggest that donors to street collections are likely to be in this category. Other users may be able to demand special purpose reports from a charity (for example, philanthropic trusts making grants) (Hyndman \& McDonnell, 2009).

Further, charities perceive regulation in general, and financial regulation in particular, to be a burden (Burt \& Taylor, 2004). As well as the direct and indirect costs of regulation, some charities may not be aware of regulatory requirements, and others may lack expertise (Burt \& Taylor, 2004). For example,

\footnotetext{
4 Information retrieved from the Charities Commission February/March newsletter 2011 downloaded from http://www.charities.govt.nz/news/newsletter/2011-03/ 1 March 2013.
} 
research following the passing of the Charities Act 1993 in England and Wales, found its imposition of reporting requirements led to a number of charities' volunteer administrators and treasurers leaving their jobs (Morgan, 2008).

The benefits charities and the public receive from reporting to a standard must outweigh the costs. Although large charities are often professionalised and likely to meet (and exceed) reporting requirements (Hyndman \& McDonnell, 2009), conversely, small charities may utilise their community links to communicate success, rather than formal financial reports. In respect of the CCEW, Fries (2003) explained they required a framework to encourage transparent reporting that was commensurate to the charity's size and also the public interest. Hind (2011) confirmed that the CCEW sought to take into account the regulatory burden on smaller charities and simplified its forms and reduced disclosure requirements for small and medium-sized charities. Yet, costs of information preparation are difficult to measure and the economic benefits of enhanced information is even more so (Brown, 1990).

Further, charity regulators may operate unsuccessfully when they do not have clear policy goals (Breen, 2009). Breen (2009) and Phillips (2012), in their analyses of fundraising regulation, note that a number of models could be used and that specific models may work best at different stages of the fundraising process. Extrapolating Breen's (2009) concern about policy goals to charity regulation in general suggests that, unless the regulator has considered the consequences of its actions, charities may bear regulatory costs unnecessarily.

Simon (1995) argues that, in response to poor regulation, governments may practise de-regulatory activities, for example providing ad hoc relief from regulation and turning a blind eye to charities' trespasses. Yet, he further notes that when charity regulators move to reduce the cost of regulation (especially reporting requirements), lawless activity can ensue. Charity reporting practice has been shown to be deficient, with shortcomings in charities' financial reports being highlighted in, for example, the UK and North America as shown in the following section. Further, while the development of charity-specific standards to guide charity preparers has advanced in England and Wales (Hind, 
2011), it remains underdeveloped in other countries, such as New Zealand (Cordery \& Baskerville, 2007).

\subsection{Charity-specific reporting in the UK and North America}

\subsubsection{United Kingdom}

From 1960 English and Welsh charities were legally required to file financial reports, yet Bird and Morgan- Jones (1981) found that charity reporting was extremely diverse, leading to reduced charity transparency and accountability. During this period the CCEW's predecessor lacked resources and the accounting framework was not charity-specific. While initially they had supported diversity in practice, Bird and Morgan-Jones (1981) found such severe inconsistencies in charity financial reports, that they argued strongly for founding principles to be established and regulation to encourage compliance.

From 1988 a Statement of Recommended Practice (SORP) could be used by charities to prepare their financial reports. However, a decade after its release, Williams and Palmer (1998) explained that charities were ignorant of the SORP, while Palmer and Vinten (1998) and Connolly and Hyndman (2001) confirmed that poor financial reporting was in effect encouraged by the failure of auditors to issue qualified audit reports on non-compliant financial reports. Alternatively, Hines and Jones (1992) argued that the voluntary nature of reporting was the most likely reason for non-compliance and poor reporting practices. While complying with the SORP remains voluntary for smaller charities (with income $<£ 25,000)$, it became mandatory from 1992 for medium and large charities, and this eventually drove compliance (Hyndman \& McMahon, 2011). Further, the SORP is regularly updated to ensure it does not digress too markedly from UK GAAP as it is applied to the public sector, given the similarity of these organizations to charities (Hyndman \& McMahon, 2011) and to ensure comparability.

The CCEW continues to have very little resource to undertake detailed checking of charities' filings. Morgan (2011) noted that problems with financial reports, including the use of different versions of the SORP, means that financial statements are not comparable across different charities, or from year 
to year for the same charity. The CCEW also requires a range of non-financial reporting, including a Trustees Annual Report and, since April 2008, a report on the extent to which the charity has undertaken activities to accomplish its objectives for the public benefit. Recent research by Morgan and Fletcher (2011) highlighted severe inadequacies with charities' (non-financial) reporting of their achievements in this respect. Such poor financial and non-financial reporting is likely to undermine the publics' confidence and result in fewer donations to charities, and potentially jeopardise government funding into the sector (Hyndman \& McDonnell, 2009).

In Scotland, the OSCR regularly undertakes a comparative study into 'small charity accounts' using a sample of 300 charities with income under $£ 25,000 .^{5}$ In the most recent study, they found that one in six charities produce financial reports which omit total income, expenditure and/or the resultant surplus or deficit. Approximately one in three charities files non-compliant balance sheets (OSCR, 2010), although Morgan (2010) notes that, if they do not balance, the OSCR rejects the whole filing (the financial report and the Trustees Annual Report).

It appears that, despite the increasing demand for transparency and accountability, there remain a number of issues in charity reporting and governance in the UK (Hyndman \& McDonnell, 2009). Users of financial statements of North American charities (and nonprofit organizations generally) also find poor quality reporting.

\subsubsection{North America}

Early research in the United States (US) by Froelich and Knoepfle (1996) compared charities' financial reports with their Internal Revenue Service (IRS) filing. ${ }^{6}$ Froelich and Knoepfle (1996) noted that the most frequent misstatement was in the expense categories, where organizations shifted salaries to Cost of Goods Sold in order to understate administration expenses. However other significant errors occur in defining fundraising expenses. From interview data they found that errors in filing of the IRS

\footnotetext{
There are approximately 25,000 charities in total registered with the OSCR.

6 Charities are defined under s.501(c)(3) of the code, may receive contributions that qualify for income tax deductions, and are regulated by the IRS.
} 
Form 990 were a result of organizations' lack of understanding of regulators' guidelines. ${ }^{7}$ Further, while financial statements were quite often prepared by accounting firms, the IRS Form 990 was filed by the organization itself and errors indicated a lack of understanding of the financial statements within the organization.

Keating and Frumkin (2003) note that nonprofit organizations' filing of their IRS Form 990 is seldom checked by the regulator (around 1.3\% of filings were checked in 1999). Further, filings are typically one to two years out of date and contain "high rates of mathematical errors, transposed digits, omitted information and information inserted on the wrong lines" (Keating \& Frumkin, 2003, p.7). Overall, a significant minority of filings omit important documents. Keating and Frumkin (2003) highlight the difficulties of requiring organizations to fill out a form (such as the Form 990) that does not comply with core accounting principles and requires extrapolation from financial reports into a number of pre-defined categories.

The relevance of Form 990 for users of financial statements was also raised by Froelich, Knoepfle and Pollak (2000). However, their study found higher levels of reliability of the totals in filed data than Keating and Frumkin (2003) and Froelich and Knoepfle (1996). Froelich et al. (2000) stated that balance sheet items were correct $99 \%$ of the time, income statements $90 \%$ of the time and that minor errors (+/- 10\%) were unimportant. Interestingly, they found that small nonprofit organizations filed correctly more often than large organizations. This appeared to be related to the inherent relative lack of complexity. Notwithstanding the errors, Desai and Yetman (2005) noted that requiring charities to file the Form 990 effectively ensured that they did not overspend charitable donations on internal compensation.

In a study of charities that submit financial reports for reporting awards in Canada, Salterio and Legresley (2010) identified that organizations with the greatest problems in developing transparent

7 In Australia, the National Standard Chart of Accounts has been developed with a taxonomic data dictionary for accounting elements which may ameliorate this issue for financial statements filed with the ACNC. 
annual reports were those with revenue between CAN\$1 million and CAN\$10 million. They hypothesised that charities in this range had a small number of staff but that they lacked the expertise to undertake a complex reporting process. Smaller organizations may well have used volunteers to develop their annual report, but their organizations were less complex and therefore the reports were more easily prepared.

This research has shown that larger organizations tend to report more transparently and meet regulators' demands more easily than small or medium-sized charities. Some research suggests that small charities also meet demands better than medium-sized charities due to their simple nature (Burt \& Taylor, 2004; Froelich et al., 2000; Salterio \& Legresley, 2010). However, the relative lack of expertise in small and medium-sized charities (Froelich \& Knoepfle, 1996) and the voluntary nature of filing (Hyndman \& McDonnell, 2009) may reduce the transparency of both small and medium-sized charities. With this in mind, the objective of this paper is to analyse how a relatively new regulator balanced its regulatory mandate with the need for parsimony and recognising poor reporting by small and medium-sized charities internationally.

\section{New Zealand - an emergent regulator}

Calls for a charity regulator in New Zealand pre-date the Charities Act 2005 by almost two decades (Cordery \& Baskerville, 2007) leading to a Charities Commission operating from early 2007. Unlike the UK which has codified 13 charitable purposes, New Zealand chose to retain the four principal divisions of charity to define what entities could be registered: "whether it relates to the relief of poverty, the advancement of education or religion, or any other matter beneficial to the community (Charities Act, 2005, s.5(1)). ${ }^{8}$

Registration in New Zealand is voluntary, but charities will register in order to benefit from tax-

8 Section 5(2) and (2A) further note that if a trust's beneficiaries, or a society's or institution's members are related by blood, they may still retain its charitable purpose; that marae are charitable if on Maori reservation land and that the promotion of amateur sport may be a charitable purpose if it is the means by which a charitable purpose referred to in $\mathrm{s5}(1)$ is pursued. 
exemption of surpluses (in pursuit of their charitable aims) and also to be able to provide a tax credit to donors. ${ }^{9}$ In the $2011 / 2012$ year, registration fees comprised $7 \%$ of the regulator's income (Charities Commission, 2012). Similar to other countries, the charities that have registered span a myriad of charitable aims, beneficiaries and size parameters. Charities are not required to take any form of incorporation; those that do may be established as a Charitable Trust, Incorporated Society, Limited Liability Company, or by a specific Act of Parliament. The liability of the members or 'owners' will be dependent on the incorporation chosen (if any).

The Charities Commission was established with 15 required functions, and a Board of between five and seven members. Its main function is to 'promote public trust and confidence in the charitable sector' (Charities Act, 2005, s.10.1(a)). This purpose accords with the regulatory theory of requiring the maintenance of the public interest. There have been three measures of the achievement of this purpose. In 2008 , a survey found that $58 \%$ of people had 'high trust' in charities with only $7 \%$ having 'low trust' (UMR Research, 2010). However, while more people had heard of the Charities Commission in the 2010 survey, (67\% of respondents compared with 57\% two years before), respondents were less likely than the 2008 respondents to use the internet-based register to access charity information (Empathy \& Charities Commission, 2010). Further, in 2010, only 55\% of respondents had 'high trust', signalling no increase in public trust and confidence. The Charities Commission responded to this result by commissioning research into which attributes of charities engender public trust. Although the results of this second survey were shared widely with the charities sector to encourage better practice in communication and practice, the 2012 survey showed a further decline in public trust and confidence to $44 \%$ (UMR Research, 2012). Nevertheless, 55\% of respondents stated that they trusted charities registered with the Charities Commission (UMR Research, 2012).

Similarly to the Charity Act 2011 for England and Wales, the New Zealand's Charities Commission was

9 From 2010 a donation of over $\$ 5$ to a charity with approved done status will allow the donor to claim a rebate of 33.33\% (Income Tax Act, 2007, s.LD1). This rebate is up to a maximum of the donor's taxable income (Tax Administration Act, 1994, s.41(A)). 
also expected to 'encourage and promote the effective use of charitable resources' (Charities Act, 2005, s.10.1(b)). Charities' filings are publicly available on the internet-based register. As it has been found that organizations with better internet disclosures of their finances fare best in the charitable contributions market (Saxton \& Guo, 2011), this is an example of how the Charities Commission informed a market for charitable donations and government funds. For example the regulator highlighted specific Christchurch charities which donors could support after the earthquakes that hit that city in late 2010 and 2011. Further, it instigated an 'open data' project encouraging software developers to mine charities' annual returns. While this allowed the Charities Commission to meet one of its ancillary requirements (to 'stimulate and promote research into any matter relating to

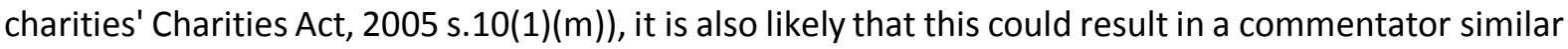
to Better Business Bureau's Wise Giving establishing itself in New Zealand.

The third major function of the Commission was to 'educate and assist charities in relation to matters of good governance' (Charities Act 2005, s.10(c)). This may be seen as an extension of the desire of the regulator to make charities more efficient. It is also an example of the light-handed compliance approach rather than a deterrence approach to enforcing the regulator's requirements. The Charities Commission actively informed charities through face-to-face and internet-based media and worked with sector leaders to explain what good governance was. No measure of their success has been found.

This light-handed approach also extended to charity filings. Charities are required to file an annual return within 6 months of their year-end along with a set of financial statements. While the computerised annual return has a number of boxes to complete, the accompanying financial reports can be in any format. There was no active checking of the filings and, as there is no requirement for an audit of the underlying financial reports (except for those in the charity's own constitution), the quality of the information may have been compromised as explained below.

Charities' financial reporting was analysed in New Zealand by Newberry $(1993 ; 1992)$ and, similarly to Bird and Morgan-Jones's (1981) UK study, she found consistent failures in charity reporting (including 
expensing of fixed assets, absence of appropriate financial statements and policies). Also similar to Bird and Morgan- Jones (1981), Newberry $(1993 ; 1992)$ was concerned that many of these failures had not been highlighted by the charity's auditors. More recent research undertaken by Hooper, Sinclair, Hui and Mataira (2008) and Sinclair (2011) also found charities' financial reports lacked appropriate information.

Yet unlike the UK, New Zealand did not respond to Newberry's $(1993 ; 1992)$ research by developing a specific charity accounting standard or SORP. ${ }^{10}$ The reasons are likely to be two-fold. First there was no charity regulator at the time to champion a reporting standard. Yet, once established, the New Zealand Charities Commission chose not to develop its own standards. This suggests an underlying constraint related to New Zealand's 'sector-neutral' or 'transaction-neutral' approach to its financial reporting standards setting which operated from 1994. Under this approach, for-profit and public and private nonprofit organizations were subject to the same financial reporting standards and private nonprofit organizations were also encouraged to produce nonfinancial information similar to that required of public sector nonprofit organizations (New Zealand Institute of Chartered Accountants, 2006).

The benefits of this sector-neutral approach included increased comparability between organizations (for example, foundations, charities with for-profit trading arms and social enterprises). It allowed for a common understanding of accountability across all preparers, whether they were public or private, for-profit or nonprofit. Also, by taking a sector-neutral approach, standard setters' effort was minimised in respect of the small 'market' of charity reporters compared to the larger 'markets' of public and private sector organizations.

Against these benefits was the drawback that New Zealand charities were denied a regime that was specifically developed for them. Accordingly, there were a number of charity-specific issues which

10 While a practice guide was produced for all nonprofit organizations (R100), it was expensive, relatively unknown and had few users. 
were not covered by the reporting standards. These omissions included accounting for fund-raising and the extrapolation of relevant ratios, and guidance on accounting for tagged and untagged legacies and bequests. Explanatory advice was developed on the treatment of these issues and the advice linked to the NZ IFRS (standards based on International Financial Reporting Standards), although these standards were mandatory only for large charities with assets greater than NZ\$30million. ${ }^{11}$ Nevertheless, in 2011, the new accounting standards regulator (the External Reporting Board) announced a move away from sector-neutrality and the future development of financial reporting standards specifically for not-for-profit entities (External Reporting Board, 2011). These standards are likely to be mandated for charities (New Zealand Government, 2012b). Further, the Charities Commission was disestablished in June 2012 and subsumed into the Department of Internal Affairs with reduced autonomy. This research was a timely analysis of the former Charities Commission.

\subsection{The New Zealand research}

The objective of this paper is to ascertain the impact of a light-handed charity regime on small and medium charities' reporting. Thus, publicly available data from charities' annual returns to the Charities Commission was accessed, as well as the financial reports charities filed contemporaneously.

This research was supported by the Charities Commission who provided raw annual return data for 400 randomly selected charities from their database. Two hundred of those charities had annual expenditure of less than $\mathrm{NZ} \$ 40,000$ and the remainder had expenditure between $\mathrm{NZ} \$ 40,000$ and NZ\$2,000,000. These ranges were selected as they are the ranges proposed for "small" and "medium" charities in the Financial Reporting Bill (New Zealand Government, 2012b). ${ }^{12}$ From this list, 300 charities were selected for further study (150 from small and 150 from medium charities), to include charities that were dispersed across regions and charitable aims. Following the downloading of the

11 At the time of writing, the NZ Dollar was worth 0.55 UK Pounds and 0.83 US Dollars.

12 It is proposed that charities with expenditure of less than $\$ 40,000$ should be allowed to report on a cash basis, while those with expenditure between $\$ 40,000$ and $\$ 2$ million should be allowed to follow "Simple Format Reporting" - a simplified accruals standard. The External Reporting Board's proposed standards for these entities can be accessed at www.xrb.govt.nz. 
charities' financial reports from the Charities Commission (www.charities.govt.nz), the efficacy of the charities' filings of summary financial data was checked against their statements to ascertain whether the charity compiled its financial accounts using a cash or accrual basis. Each charity's rules were analysed with respect to its requirement for assurance and the Charities Commission filing searched for any non-financial information that might aid understanding of the charities' activities and performance. Where charities had not filed non-financial information, the charity was contacted and requested to send any non-financial data they provided for their members and other stakeholders (for example at an Annual General Meeting). Data received was then included in the analysis. This research was undertaken between November 2010 and February 2011. It included charities' financial reports for years ended 2009 or 2010 but that were filed in 2010.

\subsection{Results}

As noted, charities' filings around the world have been beleaguered by errors and omissions. ${ }^{13}$ In this research, over $61 \%$ (184) of the 300 filings also contained errors or omissions. Table 1 shows the general categories of these filing errors and the number of filings that were affected. Errors were counted as being present or not present (' 1 ' or ' 0 '). Therefore, where the same error occurred more than once in a charity's filing it was counted only once, rather than as multiple occurrences.

\section{[Insert Table 1 here]}

The most common of the general errors reported in Table 1 was that the figures filed did not match the charity's financial reports ( $24 \%$ or 72 charities). The next most common error was missing figures, followed by figures filed with the correct numbers, but with the thousand('000')'s missing so they were in the wrong category of small, medium or large. ${ }^{14}$ These errors resulted in the definitions of the charity sample changing due to the actual expenditure being different from that filed, so that the

13 See for example, from the UK: Morgan (2011), OSCR (2010), and from North America (the US and Canada): Froelich and Knoepfle (1996), Keating and Frumkin (2003) and Ayer, Hall and Vodarek (2009).

14 The Charities Commission amended its form in early 2010 to require charities to include dollars and cents rather than, as previously, expecting them to round to the closest thousand. 
final sample included 140 small and 160 medium-sized charities (rather than 150 of each).

Froelich and Knoepfle (1996) offer an explanation for errors in US filings, stating that the person who completes the charity filing had little or no accounting knowledge. As filing requires the charity to undertake classification and reduction of the financial statements in order to fit the required categories, if filers lack accounting knowledge errors could eventuate. One New Zealand faith-based organization noted that $21 \%$ of their treasurers did not know whether their financial reporting was cash or accrual based and $19 \%$ of their treasurers had no qualification whatsoever (a further $14 \%$ did not indicate whether they were qualified or not and $15 \%$ stated they were not qualified as accountants but had other qualifications). ${ }^{15}$

The form of the annual return template may exacerbate filing problems. For example, the term 'gross income' on the pro-forma template created two types of errors; some charities did not disclose other income in their filings as, since the template asked for 'total gross income', they took the income after cost of goods sold figure (often called gross income), and omitted other income. This error also occurred with a filing whose financial reports had 'gross income' as a separate heading to 'other income' and hence 'other income' was omitted. Further, some terms were ambiguous. For example, 'cost of service provision' and 'cost of trading operations' was interpreted by some charities as meaning the cost for them to provide their service (or for them to trade) and classified their expenses accordingly. Others interpreted it as the cost for them to receive services (or for them to receive goods). The vast majority of charities omitted figures from these two categories, disclosing separately only wages, depreciation and interest with the remainder of their expenses filed as 'all other expenditure', but it was unclear as to whether they had expenditure within this category. Keating and Frumkin (2003) found similar problems with the US Form 990 in that the filing requirements did not comply with GAAP and therefore the filer needed to 'translate' their financial reports to comply with

15 Personal email to author from Van Hout. 
the regulator's demands.

From Table 1 it can be seen that financial reporting errors were also significant; the most common error in this category was that charities told the regulator that their financial reports were prepared on a cash basis, when on examination of their financial reports we found they were actually prepared on an accrual basis (this affected 77 charities of the 184 who filed errors, or $25.6 \%$ of charities). Table 2 shows more detail on where the errors lie for the 72 charities that had incorrect financial reporting. It can be seen that, while there was a small number of charities that did not provide an Income and Expenditure statement or Balance Sheet (when they had prepared financial statements on an accrual basis), the majority of errors arose from a disagreement of particular totals (Equity in $31 \%$ of filings; Surplus/Deficit in $24 \%$ of filings). This is a much higher rate than was found by Froelich, et al (2000) in the US where balance sheets were incorrect in only $1 \%$ of their sample and only $1 \%$ income and expenditure statements were incorrect.

[Insert Table 2 here]

Table 2 also shows that the errors in financial report filings by small charities are not substantially different from those of medium-sized charities. However, more than $76 \%$ of the errors in accounting basis (where charities filed accrual accounts but stated they were cash) occurred in charities that had less than $\$ 120,000$ in expenditure. Further, $26 \%$ of the total errors were found in charities with expenditure between $\$ 0$ and $\$ 10,000$.

Thirdly, we found that, although a majority (65.9\%) of charities filed their returns within the deadline, these charities were more likely to be medium-sized (70.5\%) than small $(60.8 \%)$. It can be seen in Table 3 that 102 (34.1\%) of charities filed their financial statements more than 6 months after their year end.

[Insert Table 3 here] 
Almost $44 \%$ of medium-sized charities and $30 \%$ of small charities filed their financial statements in the sixth month after their year-end. The high number of filings during the sixth month can be explained by a last minute influx to meet the submission deadline. Equally, the high number of filings during the seventh month is likely due to charities receiving a warning letter from the Charities Commission. ${ }^{16}$

\section{Discussion}

The former New Zealand Charities regulator appeared to meet the two roles identified by public interest theory. First, it was tasked with reducing information asymmetry in order to enhance charities' accountability and therefore to increase public trust and confidence. Yet, research undertaken by the Charities Commission shows there has been a decline in trust and confidence in charities in New Zealand (Empathy \& Charities Commission, 2010; UMR Research, 2010, 2012).

Further, the sample of charity filings analysed in this project showed that filings with the regulator contained a high rate of errors, as do the contemporaneously filed financial reports. These errors were not limited to small charities, but were general across the whole sample of charities with less than $\$ 2$ million in expenditure. This finding is at odds with the suggestions by Salterio and Legresley (2010) and Froelich et al. (2000) who hypothesised that smaller charities may be better at financial reporting than medium-sized charities as they have simpler reporting needs. Although the findings are limited by the random sample chosen, they confirm that small charities lack expertise (as also shown by Burt \& Taylor, 2004; Froelich \& Knoepfle, 1996). This is also borne out by the informal research undertaken by Van Hout ${ }^{17}$. Another factor in the lack of good quality reporting is the lack of a specific charity accounting regime in New Zealand, brought about by the sector-neutral focus of the accounting regulators and the paucity of advice on charity-specific matters.

16 Late filers could also be de-registered, but there is a lack of enthusiasm for this, given that a charity could receive the benefits of registration and then de-register and distribute its surpluses however it pleases.

17 Personal communication with author, September 20, 2011. 
However, against the similarity between small and medium-sized charities with respect to ordinary financial report errors, of the $34.1 \%$ of charities that filed their returns outside of the required time, small charities were worse (39.2\%) compared to medium-sized charities (29.5\%). We noted a rush to file following the receipt of a reminder letter. Such reminder letters are dependent on the regulator's resources, yet in working with a compliance approach, the Charities Commission chose a method of operation which was likely to reduce the resources it had available to 'police' charities.

The light handed compliance approach (rather than deterrence) used by the New Zealand Charities Commission prioritised proactive education and balancing of costs and benefits, so that small and medium charities had few obligations, except to file simple reports. While this may have reduced the regulatory cost on these charities, these research results show that the light-handed regime (highly voluntary) did not result in an increase of transparency and accountability in these charities. This is likely to be a reason for the lack of an increase in the donating public's trust and confidence. Hind (2011) might suggest that the CCEW's work is akin to regulating angels, yet the compliance approach does not appear to have succeeded in New Zealand. The reticence of the regulator to develop a charity-specific reporting regime and/or the slowness of the accounting regulator to do likewise is also likely to have impacted the success of the regulator in meeting its aim to develop good reporting practices.

The second reason for regulation is to create a market place (Gaffikin, 2005). By publishing the annual returns and financial information of all charities, the New Zealand Charities Commission presented data from all registered charities to any potential donor or funder. The instigation of the 'open data' project further delivered information to software developers and those seeking to mine the data which is available. In this, the New Zealand regulator showed itself to be more proactive than other 
regulators, such as the CCEW that provides charity financial reports only on demand ${ }^{18}$ and the OSCR which does not publish data at all, but invites interested parties to write to the charity concerned.

A third aspect of the New Zealand regime that is not shared by UK Charity regulators is that charities share the cost of the regulator. Theorists would suggest that this cost sharing is likely to increase the risk that the regulator may become captured by charities, but we hypothesise that this will not occur due to the diverse nature of the charities sector, the small registration fee, and the large number and range of users. Notwithstanding charities' inputs to the costs of the regulator, from 1 July 2012 the Charities Commission's core functions were moved to a government department (the Department of Internal Affairs (DIA)) and the independent Commission disestablished in an effort to reduce government's administration costs. This is despite the evidence to suggest that the former Charities Commission was under-resourced (similar to the CCEW in various periods of its existence) and that more resources were required to improve its performance. Public statements suggest that changes to DIA Charities operations will be minimised, but that the focus is on new registration and deregistration processes. While some advocacy groups who had previously been denied registration (or been de-registered) have progressed cases to be registered, (for example, Greenpeace of New Zealand Incorporated v Charities Commission [2012] NZCA 533), sector umbrella groups (for example, Association of Non-Governmental Organisations of Aotearoa, 2012) expressed distrust that a government department would now be regulating the independent charities sector.

\section{Conclusion}

There continues to be a debate about the appropriate role of regulation in the charity sector (for example, Burt \& Taylor, 2004; Hind, 2011). Regulators may represent little more than increased costs to those who are regulated, but, under public interest theory, they may also reduce information asymmetry and can be used to create a more efficient charity 'market'. It appears that New Zealand's

18 However, the CCEW's 2010/11 annual report notes that it is reviewing how it publishes and shares information on charities. 
Charities Commission was established with these precepts in mind; however, this study has shown that the light-handed nature of its activities has resulted in the regulator not achieving its aims. There are high levels of asymmetry in charities' financial reporting, as shown by the errors in the filings they make, and therefore the aim to inspire public trust and confidence has not been achieved, nor are a significant minority of charities being accountable to their users.

Similar problems with the reliability of charities' financial reports have been highlighted in a number of jurisdictions. Specifically, filings are not compliant with the allowed regime (GAAP, or a specific cash basis) and filings lack totals and segmentation especially where expenses and revenues are sensitive (e.g. fundraising). Sinclair (2011) suggests this can be attributed to charities' desire to 'look poor'. A second argument is that charities lack expertise to file appropriately presented financial statements. There is little research on capacity in this area, and it would be useful to extend this research with qualitative data on capacity and willingness to complete regulatory filing, not only in New Zealand, but also internationally.

The New Zealand Charities Commission developed methods to market charities to donors and thus prioritised the marketplace rather than the reduction of information asymmetry and an increase in information quality and comparability. However, due to its light-handed approach, the information it provided to this market was likely to be flawed. Thus its position as a regulator was undermined and did not lead to an increase in public trust and confidence in the charitable sector. The findings of this research show how necessary it is for charity regulators to utilise minimum reporting standards, and/or to utilise deterrence methods rather than light-handed compliance methods, to increase the likelihood that charities will discharge their accountability in a transparent manner. 


\section{References}

Andreoni, J. (1998). Toward a theory of charitable fundraising. Journal of Political Economy, 106(6), $1186-1213$.

Association of Non-Governmental Organisations of Aotearoa. (2012). Government mistakes undermine community charities. Press Statement. Retrieved March 2, 2013, from http://www.angoa.org.nz/angoa/?\&user_action=show_page\&page=news/2012-05-15Government-mistakes-undermine-community-charities

Ayer, S. M., Hall, M. H., \& Vodarek, L. (2009). Perspectives on Fundraising: What Charities Report to the Canada Revenue Agency. (T. M. Foundation, Ed.). Imagine Canada.

Barber, P. (2012). Regulation of US Charitable Solicitations Since 1954. VOLUNTAS: International Journal of Voluntary and Nonprofit Organizations, 23(3), 737-762.

Bird, P., \& Morgan-Jones, P. (1981). Financial Reporting by Charities. London: The Institute of Chartered Accountants in England and Wales.

Breen, O. B. (2009). Regulating Charitable Solicitation Practices - the search for a hybrid solution. Financial Accountability \& Management, 25(1), 115-143.

Breen, O. B. (2012). The Perks and Perils of Non-Statutory Fundraising Regulatory Regimes: An Anglo-Irish Perspective. VOLUNTAS: International Journal of Voluntary and Nonprofit Organizations, 23(3), 763-790.

Brown, V. H. (1990). Commentary on Accounting Standards: Their Economic and Social Consequences. Accounting Horizons, 4(3), 89-97.

Burt, E., \& Taylor, J. (2004). Striking the Regulatory Balance in the Unique Case of the Voluntary Sector. Public Money and Management, 24(5), 297-300.

Charities Commission. (2012). Annual Report 2011/2012 (p. 53).

Connolly, C., \& Hyndman, N. (2001). A comparative study on the impact of revised SORP2 on British and Irish charities. Financial Accountability \& Management, 17(1), 73-97.

Cordery, C. J., \& Baskerville, R. F. (2007). Charity financial reporting regulation: a comparative study of the UK and New Zealand. Accounting History, 12(1), 7-27.

Desai, A. M., \& Yetman, R. J. (2005). Constraining managers without owners: governance of the notfor-profit enterprise (p. 39). Cambridge, MA: National Bureau of Economic Research.

Dhanani, A. (2009). Accountability of UK charities. Public Money and Management, 29(3), 183-190.

Empathy, \& Charities Commission. (2010). The drivers of public trust and confidence: Insight Report. Wellington: Charities Commission.

External Reporting Board. (2011). Accounting Standards Framework: A multi standards approach (p. 18).

Fremont-Smith, M. R., \& Kosaras, A. (2003). Wrongdoing by Officers and Directors of Charities: A Survey of Press Reports 1995-2002. The Exempt Organization Tax Review, 25-60.

Fries, R. (2003). The Charities Commission: The Concept in the Light of English Experience. Philanthropy New Zealand Magazine, 2(34), 8-9.

Froelich, K. A., \& Knoepfle, T. W. (1996). Internal Revenue Service 990 Data: Fact of Fiction? Nonprofit and Voluntary Sector Quarterly, 25, 40-52.

Froelich, K. A., Knoepfle, T. W., \& Pollak, T. H. (2000). Financial Measures in Nonprofit Organization Research: Comparing IRS 990 Return and Audited Financial Statement Data. Nonprofit and Voluntary Sector Quarterly, 29(2), 232-254.

Gaffikin, M. (2005). Regulation as Accounting Theory. Working Paper Series 05/09, University of Wollongong: Wollongong.

Greenpeace of New Zealand Incorporated v Charities Commission. (2012). NZCA 533.

Hind, A. (2011). New Development: Increasing public trust and confidence in charities: on the side of the angels. Public Money and Management, (May), 201-205.

Hines, A., \& Jones, M. J. (1992). The Impact of SORP2 on the UK Charitable Sector: an empirical study. Financial Accountability \& Management, 8(1), 49-67. 
Hooper, K., Sinclair, R., Hui, D., \& Mataira, K. (2008). Financial reporting by New Zealand charities: finding a way forward. Managerial Auditing Journal, 23(1), 68-83.

Hyndman, N., \& McDonnell, P. (2009). Governance and Charities: an exploration of key themes and the development of a research agenda. Financial Accountability \& Management, 25(1), 5-31.

Hyndman, N., \& McMahon, D. (2011). The hand of government in shaping accounting and reporting in the UK charity sector. Public Money and Management, (May), 167-173.

Keating, E. K., \& Frumkin, P. (2003). Reengineering Nonprofit Financial Accountability: Toward a More Reliable Foundation for Regulation. Public Administration Review, 63(1), 3-15.

Morgan, G. G. (2008). The Use of Receipts and Payments Accounts for Financial Reporting by Smaller Charities: A study commissioned by the Association of Charity Independent Examiners (p. 70). Sheffield: Sheffield Hallam University.

Morgan, G. G. (2010). The use of charitable status as a basis for regulation of nonprofit accounting. Voluntary Sector Review, 1(2), 209-232.

Morgan, G. G. (2011). The Use of Charity Accounts Data for Researching the Performance of Voluntary Organisations. Voluntary Sector Review, 2(2), 213-230.

Morgan, G. G., \& Fletcher, N. (2011). Public Benefit Reporting by Charities: Report of a study undertaken by Sheffield Hallam University on behalf of the Charity Commission for England and Wales. Sheffield: Sheffield Hallam University.

New Zealand Government Tax Administration Act 1994 (1994).

New Zealand Government Income Tax Act 2007 (2007).

New Zealand Government Charities Act 2005 (2012).

New Zealand Government Financial Reporting Bill (2012). Wellington, New Zealand: New Zealand Government.

New Zealand Institute of Chartered Accountants. (2006). NZIAS-1: Presentation of Financial Statements. Wellington: Institute of Chartered Accountants of New Zealand.

New Zealand Institute of Chartered Accountants. (2007). Not for Profit Financial Reporting Guide. Wellington: New Zealand Institute of Chartered Accountants.

Newberry, S. (1992). Report on Special Issues of Accounting for Charities in New Zealand. Wellington: New Zealand Society of Accountants.

Newberry, S. M. (1993). Special Issues of Accounting for Charities in New Zeland. University of Canterbury.

Office of the Scottish Charity Regulator. (2010). Small charity accounts: a comparative study. Dundee: Office of the Scottish Charity Regulator.

Palmer, P., \& Vinten, G. (1998). Accounting, auditing and regulating charities - towards a theoretical underpinning. Managerial Auditing Journal, 13(6), 346-355.

Phillips, S. D. (2012). Canadian Leapfrog: From Regulating Charitable Fundraising to Co-Regulating Good Governance. VOLUNTAS: International Journal of Voluntary and Nonprofit Organizations, 23(3), 808-829.

Salterio, S., \& Legresley, P. (2010). Developing a culture of reporting transparency and accountability: the lessons learned from the voluntary sector reporting awards for excellence in financial reporting transparency. SSRN Working Paper.

Saxton, G. D., \& Guo, C. (2011). Accountability Online: Understanding the Web-Based Accountability Practices of Nonprofit Organizations. Nonprofit and Voluntary Sector Quarterly, 40(2), 270-295.

Simon, J. G. (1995). The regulation of American foundations : looking backward at the Tax Reform Act of 1969. Voluntas: International Journal of Voluntary and Nonprofit Organisations, 6(3), 243-254.

Sinclair, R. (2011). Understandability and Transparency of the Financial Statements of Charities. School of Business. Auckland University of Technology, Auckland.

Stigler, G. J. (1971). The theory of economic regulation. The Bell Journal of Economics and Management Science, 2(1), 3-21. 
Szper, R., \& Prakash, A. (2011). Charity Watchdogs and the Limits of Information-Based Regulation. Voluntas, 22(1), 112-141.

UMR Research. (2010). Trust and Confidence in Charities - Topline report. Wellington.

UMR Research. (2012). Trust and Confidence Survey (p. 61). Wellington, NZ.

Weisbrod, B. A. (1989). Rewarding Performance That is Hard to Measure: The Private Nonprofit Sector. Science, 244(4904), 541-546.

Williams, S., \& Palmer, P. (1998). The state of charity accounting - developments, improvements and continuing problems. Financial Accountability \& Management, 14(4), 265-279. 